\title{
LUDWIG VON MISES Y EL ROL DEL ECONOMISTA: UN ENFOQUE HISTÓRICO*
}

\author{
Víctor Espinosa Loyola \\ Fundación para el Progreso
}

\begin{abstract}
Resumen: Este artículo reconstruye la obra de Ludwig von Mises, con especial énfasis en su mirada sobre el rol del economista en la sociedad. Es posible identificar tres fases en esta trayectoria: la primera, en su infancia y juventud, marcada por una visión glorificada del Estado como motor de progreso y coordinación social; la segunda, desde la publicación de Teoría del dinero y del crédito (1912) hasta su salida de Viena en 1934, a causa de la amenaza del nazismo en Austria; y la tercera, desde su llegada a Ginebra hasta su fallecimiento en Estados Unidos. A lo largo de estos periodos se pueden apreciar dos facetas de Mises: una académica y otra como actor relevante en la discusión de políticas públicas. Este último aspecto de Mises ha sido más ignorado; sin embargo, es fundamental para entender su posición respecto al rol del economista.

PAlabras Clave: escuela austríaca de economía, liberalismo, socialismo, políticas públicas, educación económica.
\end{abstract}

Víctor Espinosa Loyola. Ingeniero comercial, máster en economía y políticas públicas por la Universidad Adolfo Ibáñez. Estudiante del máster en economía de la escuela austríaca de la Universidad Rey Juan Carlos. Investigador asociado en la Fundación para el Progreso. Email: vespinosaloyola@gmail.com.

* Versión revisada y aumentada de la presentación del autor en el I Congreso de Economía Política organizado por la escuela de postgrado e investigación de la Universidad del Desarrollo y la Fundación para el Progreso, titulada "Ludwig von Mises y la función pública del economista. 1881-1973". 


\title{
LUDWIG VON MISES AND THE ROLE OF THE ECONOMIST: A HISTORICAL APPROACH
}

\begin{abstract}
This article reconstructs the work of Ludwig von Mises around his view of the role of the economist in society. It is possible to identify three phases in this trajectory: the first, in his infancy and youth, marked by a glorified vision of the State as a motor of progress and social coordination; the second from the publication of The Theory of Money and Credit (1912) until his departure from Vienna in 1934 because of the Nazi threat in Austria; and the third from his arrival in Geneva until his death in the United States. During these periods two facets of Mises can be seen: one academic and the other as a major actor in the discussion of public policies. This latter aspect of Mises has been more overlooked; however, it is fundamental to an understanding of his position on the role of the economist.
\end{abstract}

Keywords: Austrian school of economics, liberalism, socialism, public policy, economic education.

\section{INTRODUCCIÓN}

udwig von Mises fue uno de los pensadores más destacados del siglo XX. Sus áreas de interés comprenden filosofía, historia, sociología, epistemología, pero, sobre todo, destaca por sus aportes a la ciencia económica, en la que se considera el fundador de la moderna escuela austríaca de economía. No obstante, el nombre de Mises y el paradigma austríaco no son muy familiares entre los economistas en Chile. Las razones son básicamente dos: la primera, es el predominio absoluto del enfoque Cambridge-Lausanne en la bibliografía universitaria; y la segunda, más importante aún, es el escaso interés de los economistas por la metodología. ${ }^{1}$ La formación universitaria en economía tiende a ser monolítica, es decir, se entrega una visión homogénea de la disciplina. Esto provoca que los estudiantes y profesionales consideren el estudio de la metodología como algo innecesario. Adicionalmente, existe una sobreespecialización entre los economistas del mainstream, lo que dificulta aún más la atención acerca de la epistemología y la comprensión de la ciencia económica como un todo.

${ }^{1}$ Economistas como Bruce Caldwell muestran que "la mayor preocupación parece ser que muchos economistas piensan que el estudio sobre metodología es una pérdida de tiempo" (Caldwell 1990, 64). 
Mises sostiene que la despreocupación de los economistas por la metodología los ha llevado a cometer errores como estudiar la ciencia económica con los procedimientos propios de las ciencias naturales, sin preocupación alguna respecto de los problemas epistemológicos que se derivan de tal acción. Mises señala que se ha distorsionado el rol del economista como un ingeniero social formado en métodos de intervención bajo procedimientos mecánicos. ${ }^{2}$ En palabras de Juan Carlos Cachanosky:

Sin ánimo de querer molestar a los economistas de nuestra generación, creemos que la falta de conocimiento de la historia y naturaleza de su propia ciencia afecta, en cierta manera, su avance. Hoy parecería ser que el buen economista es el que maneja las herramientas matemáticas con cierta destreza. Sin embargo, la formación matemática de los economistas se limita en general al campo algorítmico de la matemática, es decir, a los pasos "mecánicos" para la resolución de problemas, e.g., cómo se deriva o se resuelve un sistema de ecuaciones simultáneas. Pero la matemática es mucho más que eso, y Mises lo sabía, por eso no cayó en los errores de los economistas matemáticos. El enclaustramiento en la "construcción de modelos" por creer que es la manera "científica" de proceder, haciendo caso omiso de los problemas epistemológicos que implican, ha llevado a serios errores de teoría económica. (Cachanosky 2008, 31)

Se acepta y utiliza el positivismo en el diseño de políticas públicas en Chile, pero Mises demuestra sus limitaciones para comprender la acción humana al debilitar la propiedad privada y la iniciativa individual para coordinar los desajustes sociales que dan impulso a la función empresarial. Por eso, el interés de estudiar la vida y obra de Mises, desde la perspectiva histórica de su participación en la coyuntura y la discusión de políticas públicas, busca dar cuenta de que, si bien la metodología no convierte a las personas en economistas, ésta es fundamental para entenderla mejor. Para alcanzar este objetivo, la primera parte de nuestro

${ }^{2}$ Los economistas, siguiendo la tradición de Cambridge-Lausanne, han desarrollado una economía basada en la física, lo que ha contribuido a la distorsión del rol del economista, según Ludwig von Mises. Se recomienda consultar Peter Boettke (1996) y Roger E. Backhouse (2000). 
trabajo consiste en analizar los orígenes estatistas de Ludwig von Mises, es decir, su infancia y juventud ligada al socialismo y al historicismo. En la segunda parte, se estudia al Mises metodológico que participó en la coyuntura y las políticas públicas de Austria, ocupación que a su vez define su concepto del rol de los economistas. Finalmente, se estudia los efectos que tuvo el Mises educador en el desarrollo de la ciencia económica, en general, y de la moderna escuela austríaca, en particular.

\section{ORÍGENES ESTATISTAS}

Ludwig von Mises nació el 29 de septiembre de 1881, en la ciudad de Lemberg (extinto Imperio de Austria-Hungría). Perteneció a una familia judía ilustrada aunque no practicante. Su padre fue Arthur Elder von Mises (1853-1903), ingeniero en construcción que trabajó al servicio del ministerio de ferrocarriles (Kirzner 2001, 2). ${ }^{3}$ Su madre fue Adele Landau von Mises (1858-1937), quien provenía de Brody, un exclusivo pueblo judío en el borde del imperio regido por la Casa de Habsburgo. Mises tuvo un hermano menor, Richard von Mises, quien más tarde se convertiría en un reconocido físico y profesor de las universidades de Berlín y Harvard. ${ }^{4}$ La familia llegó a Austria en 1887, cuando Ludwig tenía seis años, instalándose en un departamento de los suburbios de Viena. Su personalidad estuvo influenciada por las tradiciones y estilos de vida de su familia. En este sentido, Gabriel Zanotti escribe:

[Mises] absorbió desde niño la cultura científica de la Ilustración, y fue educado por su madre en una rígida disciplina de vida y trabajo. Pero lo más interesante es que dichas familias heredan, de manera secularizada, la misión profética y en cierto sentido reformista de los profetas del antiguo testamento. (Zanotti 2010,112)

Su madre jugó al parecer un papel fundamental en la formación de Mises y su deber de transformar el mundo mediante el uso de la razón. Por otro lado, heredó de su padre el entusiasmo, la determinación, la in-

${ }^{3}$ Los antepasados de Mises estuvieron fuertemente implicados en las dos principales empresas ferroviarias de Galicia, sirviendo como miembros de la junta y los banqueros (Hülsmann 2007, 9).

${ }^{4}$ Para una aproximación a la vida y obra de Richard von Mises véase Föllmer y Küchler (1998) y Siegmund-Schultze (2001). 
teligencia, el amor por su patria, el liderazgo sin pretensiones y la escritura clara (Hülsmann 2007, 10). También adquirió una inclinación hacia el servicio público que, tal cual su padre, lo interpretaría como trabajo al servicio del gobierno, con el fin de canalizar sus conocimientos y energías en mejorar la vida de las personas. En efecto, la misión profética, la determinación y la visión reformista para ayudar a la sociedad fueron aspectos que estarían presentes durante la vida y obra de Ludwig von Mises. Según Mises y Sennholz (1978), a los once años de edad, ya era un apasionado lector y conocedor de la contingencia política de su país. Estaba al tanto de las disputas entre el gobierno y los partidarios del marxismo.

Desde 1892 a 1900, Mises realiza sus estudios en el Akademisches Gymnasium, que era el lugar de educación para las mejores familias judías de Viena, donde adquirió una cultura humanista. En 1900, Mises comienza sus estudios de leyes en la Universidad de Viena, lugar influenciado por la escuela historicista alemana, en la que muchos de sus miembros tenían fuertes inclinaciones socialistas y abiertamente pidieron más intervención del gobierno. Algunos incluso abogaban por la abolición completa de la propiedad privada (Hülsmann 2007, 78).

Mises comenzó su carrera como un economista historicista, sin embargo, tenía objeciones a esta escuela y discutía sobre las mismas con personalidades como Ludo Hartmann, Alfred Pribram y Max Weber. ${ }^{5}$ Además, la Universidad de Viena había contratado a Carl Grünberg, quien fue maestro de Mises, además de ser un historicista y el principal exponente del austromarxismo. El seminario de Grünberg había reforzado en Mises las ideas que traía de su adolescencia, una visión glorificada del Estado como fuerza motriz en una gestión ilustrada de la economía y la sociedad (Hülsmann 2007, 79). Grünberg introdujo a Mises en el estudio de la historia económica enfocada en las medidas intervencionistas de los gobiernos. ${ }^{6}$ Del mismo modo, Kirzner (2001) cuenta que el austríaco escribe y publica una serie de investigaciones sobre políticas públicas en Austria desde la perspectiva del historicismo alemán. Muñoz (2004) señala que los economistas, influidos por el historicismo, enfo-

\footnotetext{
${ }^{5}$ Véase Crespo (1997) y Anderson (2004).
}

${ }^{6}$ Entre sus trabajos de investigación destacan la historia de la legislación laboral en Galicia, bajo la guía de Carl Grünberg y, en 1905, un estudio sobre la legislación industrial en Austria. 
caron sus estudios en el socialismo, el movimiento obrero y un replanteamiento del marxismo, en el que el rol del economista era organizar la sociedad, es decir, la ingeniería social. En palabras de Mises:

Cuando la realidad no se ajustaba al deseo del reformador y las utopías resultaban irrealizables, el fracaso se atribuía a la imperfección moral de los humanos. Los problemas sociales se consideraban cuestiones puramente éticas. Para edificar la sociedad ideal sólo se precisaba contar con rectos gobernantes y súbditos virtuosos. De este modo, cualquier utopía podía convertirse en realidad. (Mises 1949, 2)

En este periodo, el austríaco era partidario de reformas sociales y el intervencionismo estatal en la economía. Pensaba que si una reforma de gobierno no cumplía sus objetivos era porque no se había gastado lo suficiente o porque el gobierno no había sido bastante firme como para hacer cumplir sus medidas (Bien Greaves 1994, 1). Simpatizaba con la perspectiva fabiana y tenía claro sus objetivos reformadores en una Viena que tendía política y económicamente hacia el socialismo. En este sentido, Mises afirma: "Cuando entré en la universidad, yo también era un completo estatista [intervencionista]. Pero en contraste con mis compañeros, yo era conscientemente antimarxista" (Mises y Sennholz 1978, 11).

Mises nació y creció en la época en la cual surgía la escuela austriaca de economía de la mano del economista Carl Menger (18401921) y sus discípulos Eugen von Böhm-Bawerk (1851-1914) y Friedrich von Wieser (1851-1926), con sus estudios de la subjetividad del valor y el concepto de eficiencia dinámica del mercado. ${ }^{7}$ Sin embargo, fueron las propias investigaciones de Mises sobre políticas públicas, sus lecturas sobre historicismo y marxismo, y las interacciones profesio-

${ }^{7}$ La escuela austriaca de economía surge en 1871 de la mano de Carl Menger con la publicación de su libro Principios de economía política, sentando las bases de la ley subjetiva del valor y el individualismo metodológico, que son sus cimientos. Según economistas como Juan Carlos Cachanosky, "el gran hito que separa al pensamiento de la escuela austríaca del resto comienza en la teoría del valor. Las teorías de Jevons, Walras y Menger tienen diferencias mucho más profundas que las que se señalan generalmente en los textos de historia del pensamiento económico. Como dice Mises, el paso de la teoría clásica del valor a la teoría subjetiva implicó mucho más que la sustitución de una teoría poco satisfactoria por otra mejor. Este paso tuvo consecuencias importantes, tanto para la teoría del mercado como para el ámbito y método de la economía" (Cachanosky 2008, 18). 
nales con Eugen von Philippovich y Robert Mayer, ambos discípulos de Menger, los acontecimientos que le generaron muchas interrogantes sobre el intervencionismo estatal y el rol del economista como ingeniero social. ${ }^{8}$ Se comienza a interesar en epistemología y ve a la escuela mengueriana como el último curso de esperanza intelectual para la preservación de la libertad y la civilización ante los peligros del estatismo y el marxismo (Kirzner 2001, 5). Por este motivo, Mises lee los Principios de economía (1871) de Carl Menger en 1903, y comienza a rebelarse contra la ideología y metodología dominante del historicismo y el socialismo. A partir del estudio de la ley subjetiva del valor, Mises descubre regularidades en los procesos sociales que hacen que la acción del gobierno no sea omnipotente.

Mises termina su primera etapa universitaria con honores en las áreas de estudios judiciales, ciencias sociales e historia de la ley, obteniendo el grado de doctor en leyes y economía en 1906, tiempo en que asistió a los seminarios de Eugen von Böhm-Bawerk en la Universidad de Viena, los cuales consistían en discusiones participativas sobre los principios de la economía. ${ }^{9}$ Las discusiones giraban en torno a la teoría del valor (Mises y Sennholz 1978, 39). En el seminario abundaban las discusiones sobre teoría marxista, metodología y las teorías clásicas de Böhm-Bawerk sobre el capital e interés (Kirzner 2001, 40). Estas actividades permitieron a Mises profundizar su conocimiento acerca de los fundamentos epistemológicos de la escuela austríaca y formar también una visión crítica de la función de los economistas de su época como

${ }^{8}$ Bien Greaves (1994) menciona uno de los trabajos de Mises sobre la situación de la vivienda en Austria, a partir del cual se percató de que los impuestos en los materiales de construcción habían aumentado los costos para los proyectos inmobiliarios. Además, el control de los alquileres hacía inútil la inversión en viviendas. Como consecuencia de estos estudios, Mises comenzó a darse cuenta de que los problemas de escasez y el alto costo de las viviendas se debía a la intervención del gobierno en la economía. En efecto, los empresarios deseaban abrir nuevas fábricas y contratar más trabajadores, pero su acción se veía reprimida por los impuestos y la creciente regulación del gobierno.

${ }^{9}$ Böhm-Bawerk comenzó a dictar su famoso seminario en la Universidad de Viena en 1905, tras concluir su carrera profesional como ministro de finanzas del imperio austro-húngaro. Entre las personalidades que asistían a su seminario estaba Ludwig von Mises, Joseph Schumpeter y los pro marxistas Rudolph Hilferding, Otto Bauer, Otto Neurath y Nikolai Bukherin. Para analizar en mayor profundidad la vida y obra de Eugen von Böhm-Bawerk. Véase Hülsmann (2007, 141-150). 
diseñadores de políticas, al distorsionar el análisis científico mediante juicios personales sobre cómo deberían ser las cosas, junto con imponerlas al resto mediante la coacción del Estado. ${ }^{10}$

\section{PRIVATSEMINAR Y CÁMARA DE COMERCIO}

Luego de haber participado en diversos proyectos de investigación económica, en 1909 Mises es contratado como asesor económico en la Cámara Austríaca de Comercio, una institución cuasigubernamental ocupada de las políticas industriales y comerciales nacionales. Desempeñó dicha labor hasta el año $1934 .{ }^{11} \mathrm{Su}$ trabajo en la cámara y la asistencia a los seminarios de Böhm-Bawerk le entregaron las herramientas para un entendimiento acabado de los procesos de mercado desde la eficiencia dinámica de la escuela austriaca. Es así como va formando su primer paradigma en la teoría económica, sosteniendo largas discusiones con Menger y Böhm-Bawerk (Mises y Sennholz 1978, 35), que culminarían con la publicación de su primer libro: Teoría del dinero y del crédito (Mises 1912). ${ }^{12}$ Murray Rothbard sugiere:

$\mathrm{Al}$ ver cómo las teorías de sus mentores se estancaban, mientras el socialismo e intervencionismo avanzaban cada vez con ma-

${ }^{10}$ Los seminarios de Böhm-Bawerk "tenían lugar todos los viernes a las cinco de la tarde y duraban aproximadamente una hora y media. Contaba con una audiencia de cincuenta o sesenta personas y había una biblioteca propia para los integrantes del seminario. Los trabajos presentados ocupaban un lugar secundario; tenían el objeto de introducir el tema y no el de convertirse en el centro del debate" (Cachanosky 2008, 11).

${ }^{11}$ Mises participa en la Verein fur Socialpolitik, una asociación de economistas dedicada a discutir políticas sociales, que fue fundada por Gustav von Schmoller y estaba compuesta por profesionales cercanos al historicismo y el socialismo. Las contribuciones de Mises al debate, junto con las de Max Weber, cambiaron la orientación de dicha organización hacia una pluralidad de ideas. Véase Hunold (1961, 16).

${ }^{12}$ El objetivo del libro, según Mises, "era combatir el inflacionismo, es decir, aquella política económica que recurre, para resolver los distintos conflictos que se presentan, a aumentar la cantidad de dinero, un fenómeno moderno asociado a la aparición y consolidación de los bancos centrales y el dinero fiduciario. Se trata de la primera obra de importancia de un autor que destacaría luego por sus trabajos sobre la imposibilidad del cálculo económico en aquellos sistemas que prescinden de los precios de mercado y lo confían todo a la planificación centralizada de sus economías. En esta ocasión aborda un tema que afecta también al cálculo económico en las economías de mercado como es el del valor objetivo de cambio de su moneda" (Mises 1912, XXXIX). 
yor violencia e influencia en economistas y gobiernos europeos, Mises advirtió que era preciso avanzar más; que la escuela no sabía cómo llegar a las conclusiones últimas que de sus propios razonamientos derivaban; había algunas que era preciso colmar. (Rothbard 1973, 17)

Adicionalmente, Peter Boettke (1987) muestra que Mises (1912) construye sobre el trabajo de Menger, aplicando la ley de utilidad marginal al dinero con el fin de elaborar un puente entre la teoría de los precios y la teoría monetaria. La publicación de este libro le permitió además ser admitido como Privatdozent en la Universidad de Viena en 1913, es decir, profesor de economía asalariado. En este momento Mises deja de asistir al seminario de Böhm-Bawerk ${ }^{13}$ y funda el "Instituto Austríaco de Investigaciones sobre el Ciclo Económico y su propio Privatseminar, al que asistieron muchos de los más destacados estudiosos de la época" (Benegas Lynch 1991, 184). De este modo, comienza a enseñar la importancia de la libertad política y económica, con lo que pone en marcha la incipiente moderna escuela austríaca de economía. ${ }^{14}$ Se propone el objetivo de "salvar a la civilización europea de sus enemigos: los socialismos, los nacionalismos, los militarismos, intervencionismos y autoritarismos diversos" (Zanotti 2010, 112).

Existe una faceta de Mises que ha sido más ignorada en la literatura. Ella es su participación como especialista en políticas gubernamentales, en las que tuvo que razonar y escribir sobre coyuntura. ${ }^{15}$ En

${ }^{13}$ En 1913, un año antes de la muerte de Böhm-Bawerk, el tema de discusión en el seminario fue el libro de Mises (Mises y Sennholz 1978, 40).

${ }^{14}$ Entre los asistentes al seminario de Mises podemos encontrar a algunos de los grandes nombres en economía del siglo XX: Gottfried Haberler, Friedrich A. Hayek, Fritz Machlup, Felix Kauffman, Oskar Morgenstern, Lionel Robbins, Paul N. Rosensten-Rodan, Rudolf von Strigl, Alfred Schütz, Erich Voegelin y Emanuel Winternitz. Después del seminario, el grupo se iba a comer al restaurante italiano Ancora Verde, donde continuaban las discusiones, luego de lo cual algunos de los participantes solían proseguir con la tertulia en el café Kunstler, que quedaba frente a la universidad (Mises 1986, 177-179).

${ }^{15}$ Los trabajos de coyuntura que Mises escribió cuando fue asesor full time de la cámara de comercio vienesa están casi todos publicados a raíz de los llamados "The Lost Papers": Mises (2012): Monetary and Economic Policy Problems Before, During, and After the Great War; Mises (2002): Between the Two World Wars: Monetary Disorder, Interventionism, Socialism, and the Great Depression; y Mises (2000): The Political Economy of International Reform and Reconstruction. 
efecto, en la cámara de comercio estuvo encargado de analizar políticas públicas y aconsejar a los gobernantes. Consideraba que el rol del economista debiera limitarse a la investigación y enseñanza de la teoría económica y las consecuencias de diferentes cursos de acción, pero no al diseño de políticas, que implica hacer un pronunciamiento ético y arbitrario (Rothbard 1993, 1). Mises estaba consciente de los problemas que le traería entrar en el mundo más provocador y polémico de la política. A pesar de sus esfuerzos por investigar y demostrar los efectos de determinadas políticas para la sociedad, el gobierno impulsaba medidas contraproducentes respecto a sus propios objetivos que, siguiendo intereses ideológicos, tendían a coartar las libertades de las personas. Aunque no aspiraba a una carrera en el gobierno, a Mises no le quedaban otras alternativas puesto que "la cámara de comercio fue el único lugar que le permitió trabajar en Austria. El profesorado estaba cerrado para él, ya que las universidades estaban buscando intervencionistas y socialistas" (Rothbard 1993, 2).

Durante la Primera Guerra Mundial, Mises experimentó las dificultades de la contienda en primera persona. Estuvo en el servicio activo como un primer teniente, pero después de contraer la fiebre tifoidea en 1917 fue llamado de nuevo a Viena para trabajar en la división de economía del departamento de guerra (Kirzner 2001, 6). Al finalizar el conflicto era el principal consejero económico del gobierno, aunque estuvo en desacuerdo con el Estado austríaco (Rothbard 1993, 3). Trató de combatir el estatismo y la inflación del gobierno en un entorno profesional partidario del intervencionismo y políticamente adverso a las ideas del laissez-faire. Según Boettke (1987), Mises afirmaba que su experiencia durante la guerra lo llevó a plantear cuestiones fundamentales de la economía y la política social, con preguntas respecto a si el capitalismo, el socialismo o el intervencionismo constituyen un adecuado sistema de cooperación social. Estas investigaciones llevan a la publicación de Nación, Estado y economía (Mises 1919), texto en el que analizó y criticó la guerra del socialismo y las ideas del nacionalsocialismo.

Luego, Mises advierte falta de atención de los economistas al estudio de la economía socialista: "Se subestimaba la importancia de los precios para la planificación central, ya que la misma lógica del equilibrio general que Walras había desarrollado para analizar el capitalismo era aplicada al socialismo" (Lavoie 1981, 43). Así, publica su ensayo 
Cálculo económico en el sistema socialista (Mises 1920), que da inicio al debate entre economistas austríacos y neoclásicos, sobre la imposibilidad del cálculo económico en un sistema socialista desde una perspectiva dinámica del mercado. Mises ofreció su desafío: que un cálculo económico racional bajo el socialismo es imposible (Boettke 1987, 10). Él argumentó que sin propiedad privada de los medios de producción no puede existir mercado. Sin mercado - planteó- no existen precios de mercado expresados en dinero para los medios de producción, entonces el cálculo no es posible y los planificadores sociales no podrán hacer uso de la contabilidad ni de la evaluación de proyectos, es decir, no es posible economizar recursos. En otras palabras:

La demanda en el mercado de bienes de consumo hace que se imputen valores a los factores en la cadena productiva para responder a las necesidades expresadas por requerimientos de aquellos bienes finales. La única forma de coordinar la producción es la propiedad privada de los factores de producción (y no tan sólo de los bienes de consumo), lo cual constituye el único procedimiento posible para el cálculo económico sobre el que puede llevarse a cabo la evaluación de proyectos y la contabilidad. (Benegas Lynch 1993, 107) ${ }^{16}$

Los precios en dinero, según Mises, surgen como resultado involuntario de interacciones voluntarias de una multitud de individuos que persiguen sus fines y necesidades particulares. Los precios que emergen en un mercado transmiten conocimiento sobre la escasez relativa de los bienes, que sirve como ayuda a las mentes humanas para realizar un cálculo racional (Boettke 1987, 10). ¿Cómo podrían los planificadores centrales saber qué proyectos son económicamente factibles y cuáles no en función de los fines y necesidades de todas y cada una de las personas? Mises concluye que eso es imposible.

Su actividad más importante como consejero del gobierno austríaco fue el intento de detener la inflación desenfrenada en esta nación, y así evitar una hiperinflación causada por la política monetaria de postguerra. Junto a su amigo Wilhelm Rosenberg, economista, jurista y ex estudiante de Carl Menger, se opusieron al déficit y la creación

\footnotetext{
${ }^{16}$ La cursiva es mía.
} 
de dinero por parte del gobierno. ${ }^{17}$ En 1922, se logró la estabilización de la moneda y esto evitó en Austria la crisis que sufriría Alemania al año siguiente. El problema fue que la estabilización era sólo la mitad del camino a casa. A pesar de los esfuerzos de Mises y Rosenberg, el gobierno austríaco continuó su política de inflación, expansión bancaria del crédito, déficits y crecimiento del Estado de bienestar (Rothbard 1993, 4). Ese mismo año escribió El socialismo. Análisis económico y sociológico (Mises 1922), texto en el que exploró mediante la ciencia económica los problemas del socialismo desde un punto de vista dinámico. En esta obra podemos apreciar su visión escéptica respecto de la contingencia política y de la función del economista de su época. ${ }^{18} \mathrm{En}$ efecto, Mises manifiesta que:

La costumbre de escribir y hablar de los hechos de la política económica sin estudiar a fondo, concienzudamente, y hasta en sus últimos resultados los problemas implicados, resta todo valor intelectual a la discusión pública de las cuestiones vitales que interesan a la sociedad humana, y conduce la política por caminos que llevan a destruir toda civilización (...). Nuestros contemporáneos creen que se puede juzgar, sin preparación, los problemas que constituyen el objeto de ciencias como la economía política y la sociología. Consideran que un director de empresa o un empleado de sindicato pueden tener suficiente competencia, sin otra razón que su función misma, para decidir cuestiones que interesan a la economía política. Es necesario desenmascarar a ese locuaz aficionado, a ese falso economista, que sólo es un ignorante. (Mises 1922, 30)

${ }^{17}$ Se llegó a un punto de inflexión cuando, a finales de mayo de 1922, monseñor Seipel Ignatz asumió la cancillería con el firme propósito de sacar a Austria de la pesadilla financiera. Él ya tenía cierta experiencia en el manejo de situaciones catastróficas en la política austríaca, después de haber sido miembro del último gobierno imperial bajo Heinrich Lammasch en 1918, cuyos asesores fueron Ludwig von Mises y Wilhelm Rosenberg, quienes lo convencieron de la necesidad de una reforma para combatir el desempleo y la inflación (Hülsmann 2007, 483).

${ }^{18}$ En estos años Mises comenzó a expandir sus responsabilidades en la cámara de comercio, involucrándose directamente en la política central y los problemas políticos del día a día, siendo catalogado como "el economista del país" (Mises y Sennholz 1978, 73). Sólo unos pocos lo ayudaban y todos los partidos políticos estaban en su contra, ya que las recomendaciones de Mises iban a contracorriente de sus intereses. Secretarios y líderes de los partidos lo visitaban seguido en su oficina de la cámara de comercio, con el fin de intentar influenciarlo. 
Es posible advertir un Mises desilusionado de las acciones de los gobernantes que no consideran sus advertencias y, por el contrario, aumentan el intervencionismo influenciados por sus vecinos: el nacionalsocialismo alemán, el fascismo italiano y el socialismo soviético. Su preocupación por la función del economista se conecta con el interés de encontrar una metodología libre de pronunciamientos antojadizos, que evite los problemas del intervencionismo y el socialismo. El éxito de esta metodología dependerá en gran medida de su capacidad para comprender las normas rectoras de la acción humana, y así analizar las consecuencias formales de determinadas políticas en el proceso de interacción y cooperación social. Mises continúa:

Sé muy bien que puede tener la apariencia de acto incomprensible pretender hoy, por medio de una demostración lógica, convencer a los adeptos de la idea socialista del absurdo y de la locura que entrañan sus concepciones. Sé muy bien que no quieren oír, que no quieren ver y que, sobre todo, no quieren pensar, inaccesibles a todo argumento. Pero están formándose nuevas generaciones, con la inteligencia y los ojos muy despiertos. Ellas considerarán las cosas sin parcialidad, sin sesgado partidismo, para obrar según su leal saber y entender. (Mises 1922, 31)

A juicio de Mises, el gobierno impulsa acciones irresponsables y carentes de rigurosidad científica. Asimismo, las escuelas de economía forman ingenieros sociales cuyo fin es diseñar e implementar métodos de intervención. El economista se convierte en un planificador que desea "privar a todas las demás personas de la facultad de planificar y de obrar conforme a sus planes. Sólo tiene un objetivo: la preeminencia absoluta, exclusiva, de su propio plan" (Mises 1922, 529).

Dado que observa el presente perdido, comienza a ver esperanzas en las generaciones del futuro y escribe Liberalismo. La tradición clásica (Mises 1927) como obra complementaria al Socialismo (Mises 1922), construyendo una alternativa liberal a los problemas de su tiempo. En este sentido, Mises muestra una confianza en la razón humana. Pensaba que la defensa de la economía libre era un asunto de vital importancia para la civilización, el futuro de la humanidad y su existencia. Si el economista participa en el gobierno altera el carácter científico de la economía, ya que está obligado a pronunciarse sobre los fines de las 
personas según los objetivos del pensamiento político al que adscribe, que en última instancia son arbitrarios. Así, Mises (1927) argumenta que el economista no debe ser un ingeniero social que ayuda al gobierno a imponer un punto de vista particular al resto mediante la violencia institucional, ya que, además de afectar la libertad de las personas, sus consecuencias son contraproducentes. Su rol, más bien, debe ser la educación económica en los principios del valor absoluto y primario de la libertad, de la propiedad privada, del estado de derecho, de la tolerancia y la cooperación entre los individuos y los pueblos, y del protagonismo de la iniciativa individual y la sociedad civil frente al gobierno omnipotente, entrometido y dispensador interesado de favores, subvenciones y privilegios (Mises 1927).

Continuando su trabajo en la cámara de comercio y participando en la coyuntura, Mises se dedica a investigar las preguntas fundamentales sobre epistemología y metodología de las ciencias humanas para clarificar su posición sobre la función del economista (Boettke 1987, 10). El resultado es su obra Problemas epistemológicos en economía (Mises 1933), en el que presenta la praxeología, una teoría general de la acción humana. ${ }^{19}$ Esto es, existen leyes y principios a priori presentes en toda acción humana, distintos de aquellos que rigen las ciencias naturales. Mises critica el historicismo y, su variante más moderna, el positivismo, entendido como el estudio de las ciencias sociales mediante los mecanismos propios de las ciencias físico-naturales:

El naturalismo presupone que las leyes empíricas pueden derivarse a posteriori del estudio de los datos históricos. A veces presupone que estas leyes son válidas al margen del tiempo y el lugar, otras veces que sólo son válidas para ciertos periodos, países, razas o nacionalidades. La gran mayoría de los historiadores rechazan ambas versiones de esta doctrina. Ésta es también generalmente rechazada por quienes son partidarios del historicismo y no admiten que, sin la ayuda de una teoría a priori de

${ }^{19}$ Pese a que el adjetivo "praxeológico" evoca inmediatamente a Ludwig von Mises y a la escuela austríaca, el término "praxeología" fue utilizado con anterioridad por Espinas. Así lo explica Mises: "El término praxeología fue empleado por primera vez, en 1890, por Espinas. V. en su artículo "Les Origines de la technologie", Revue Philosophique, año XV, XXX, 114-115, y el libro publicado en París en 1897 con el mismo título" (Mises 1949, 4). 
la acción humana, el historiador no sabrá cómo tratar su materia y le sería imposible resolver cualquiera de sus problemas. Estos historiadores sostienen por lo general que están en condiciones de desarrollar su trabajo totalmente al margen de cualquier teoría. (Mises 1933, 42)

Dado que es imposible que los economistas conozcan las valoraciones subjetivas de cada persona, la que, a su vez, se encuentra en continuo cambio, el positivismo implica interpretar la historia de acuerdo a la información que dispone el científico. Por lo tanto, toda política pública que emerja de dicho experimento y dichas variables utilizadas no es generalizable a toda persona, tiempo y lugar. Las consecuencias de esas políticas se traducen en coartar la libertad de los individuos por medio de la violencia institucional.

En 1933, Adolf Hitler llegó al poder en Alemania liderando el partido nacionalsocialista con un programa expansionista, antisemita y anticapitalista. Esto arriesgaba la independencia de Austria, al tiempo que Mises temía por su vida al ser abiertamente contrario a tal ideología. "Cabe imaginar el golpe que sufre este reformador cuando es obligado a dejar su querida Viena para refugiarse de los nazis" (Zanotti 2010, 113). En 1934 su amigo William E. Rappard (1883-1958) le consigue una oferta para ser profesor full time en el Instituto de Relaciones Internacionales de Ginebra y, así, escapa a Suiza.

\section{GINEBRA Y ESTADOS UNIDOS}

La estadía de Mises en Ginebra significó uno de sus periodos más tranquilos desde el punto de vista académico. Desde 1934, se desempeñó como docente e investigador a tiempo completo, alejándose de la participación en la contingencia política. ${ }^{20}$ Procede a escribir su tratado de economía, La acción humana, en que sistematiza todo su pensamiento praxeológico y le dedica una parte completa al papel de la economía en la sociedad. Sin embargo, su publicación se ve silenciada por la

${ }^{20}$ En 1938, Mises se casó con Margit Herzfeld Sereny, ex actriz y viuda de Fernando Sereny, madre de Gitta Sereny, a quien había conocido en 1925, y que se convertiría en su compañera de vida. Véase Margit von Mises (1976). 
llegada de los nazis a Viena en $1938 .{ }^{21}$ Sumado a ello, la situación europea de entonces no puede asegurarle que los nazis no invadirían Suiza, por lo que decide migrar hacia Estados Unidos. ${ }^{22}$ De igual manera, a finales de la década de 1930, y ante la avanzada del socialismo nazi, prácticamente todos sus cercanos, amigos y discípulos habían emigrado de Europa. Así, la incipiente escuela austríaca, que comenzaba a posicionar sus planteamientos en Europa, se desintegró. ${ }^{23}$

En 1940, Mises llega a América con 60 años a un ambiente académico que lo ignora. Era esperado por sólo cuatro personas: Leonard Read, Henry Hazlitt, Alfred Schütz y Fritz Machlup. Según Zanotti (2010), es evidente la amargura de Mises en los Estados Unidos, donde no lo reconocen. El austríaco era antikeynesiano, contrario al intervencionismo monetario (lo que le valdría el rechazo de Chicago) y también totalmente contrario al positivismo en las ciencias sociales. En 1940, desaprobar el positivismo no significaba sino el ostracismo académico ya que éste era la corriente dominante en el estudio de la economía. ${ }^{24}$ Además, había escrito poco en inglés. Dice entonces que "deja de ser

${ }^{21}$ Un 11 de marzo de 1938, tropas alemanas al mando de Himmler entraron en la capital austríaca, y dos días después un pelotón de la Gestapo irrumpió en su domicilio. No lo encontraron, pero confiscaron su biblioteca, sus documentos personales y familiares y su correspondencia, archivos y manuscritos. Ellos nunca fueron vistos de nuevo. Mises y sus amigos dieron por supuesto que habían sido destruidos, ya sea por los nazis o en la destrucción de la guerra. Pero ese no fue el caso. Los empaquetaron en 21 cajas, y nada más se supo de ellos hasta que, en los primeros días de mayo de 1945, el ejército soviético los localizó. Los comunistas se los llevaron y clasificaron, y quedaron almacenados en Moscú hasta que en octubre de 1996 fueron hallados por Richard Ebeling y su esposa. Resulta paradójico que los socialismos alemán y ruso clasificaran y conservaran los escritos de su principal crítico en el siglo XX. Véase Ebeling (2004).

22 Hülsmann afirma que los nazis estuvieron a dos días de llegar y asesinar a Mises (Hülsmann 2007, 726).

${ }^{23}$ Sobre la desintegración y el renacimiento de la escuela austríaca, véase Schulak y Unterköfler (2011).

${ }^{24}$ El economista Iván Carrino afirma que, "para el positivismo lógico, sólo eran ciencias aquellas disciplinas que emplearan el método hipotético-deductivo, siempre y cuando sus enunciados pudieran verificarse mediante comprobación empírica — de aquí que también Mises lo llame empirismo. Todo lo demás, sostenían, carecía de sentido y pertenecía a la vaga literatura metafísica (...). Mises explica que la crítica del positivismo es errada porque confunde el apriorismo de la matemática y la geometría con el de las ciencias de la acción humana (la praxeología)" (Mises 1962, 14-15). 
un protagonista de la civilización europea [para pasar a] ser un historiador del declive europeo" (Mises y Sennholz 1978, 27).

Mientras que a los exiliados socialdemócratas se les abría la puerta en las universidades estadounidenses, el austríaco vivía del salario que recibía de la Fundación Rockefeller, por asesoramiento internacional, además de lo que obtenía de trabajar como investigador en la National Bureau of Economic Research (NBER). Luego, "la William Volker Fund en 1944, decide pagarle como profesor visitante en la Universidad de Nueva York" (Zanotti 2010, 114). Si bien no es contratado directamente por la universidad, ésta acepta que Mises sea profesor visitante con un seminario cada quince días y un humilde salario. ${ }^{25}$ Éste fue su trabajo hasta retirarse a los 87 años. Pero Mises aún conservaba su espíritu insistente y reformador, por lo que vuelve a fundar su seminario en la Universidad de Nueva York, ${ }^{26}$ a la par que reescribe La acción humana, que publica oficialmente en 1949. Juan Carlos Cachanosky nos cuenta la insistencia de Ludwig von Mises en formar economistas con conocimientos multidisciplinarios, especialmente con acento en metodología y epistemología:

El nivel de conocimiento que exigía de un economista también le acarreaba en ocasiones quejas de sus alumnos. Consideraba que nadie podía ser un buen economista a menos que estuviese versado en matemática, física, biología, historia y jurisprudencia. Cuando un estudiante de economía le reclamó que nadie lo podía obligar a estudiar todo eso, la reacción de Mises fue: "Nadie le

${ }^{25}$ Cuenta José Carlos Rodríguez que "Henry Hazlitt, que conocía su obra, logró que se publicaran varios artículos en The New York Times en 1942 y 1943; artículos que llamaron la atención de la National Association of Manufacturers (NAM), que en adelante le otorgaría otra asignación anual. En 1945 Leonard Read creó la Foundation for Economic Education, volcada a la participación en coyuntura, junto con la educación de las generaciones futuras en los principios liberales, y Mises formó parte de la misma desde el comienzo. En 1946 logrará la ciudadanía estadounidense" (Rodríguez 2009). Las cursivas son mías.

${ }^{26}$ A grandes rasgos, puede decirse que las características de este seminario eran similares a las del que se llevaba a cabo en Viena. Los participantes más destacados fueron Robert G. Anderson, Percy L. Greaves, Henry Hazlitt, Israel M. Kirzner, George Koetber, Joseph Kecheissen, Robert H. Miller, Toshio Murato, Sylvester Petro, George Reisman, Murray N. Rothbard, Hans F. Sennholz, Louis Spadaro y Bettina Bien. Las comidas que congregaban a la mayor parte de los asistentes a este seminario se denominaron "The Mises Circle". 
pide o lo obliga a usted a que sea economista". Idéntica exigencia requería en el manejo de idiomas. En muchas ocasiones, en la Universidad de New York, leía citas en francés y alemán. Cuando alguien se quejó, aduciendo que no hablaba ni francés ni alemán, la respuesta fue: "Apréndalos, usted se ha involucrado en actividades académicas". (Cachanosky 2008, 31)

La acción humana (Mises 1949) expone los principios y fundamentos esenciales de la ciencia económica austríaca, encuadrada en una teoría general de la acción humana o praxeología, siguiendo una metodología apriorístico-deductiva en la línea de la concepción subjetivista. De esta manera, una de las tareas del economista es descubrir esas teorías o leyes que sean válidas para cualquier tiempo y lugar. En epistemología existen regularidades en la estructura lógica de la mente humana, que permiten a los economistas estudiar la acción humana de forma objetiva.

Según Mises, aquellos que rechazan el apriorismo niegan la existencia de leyes o principios universales en el mundo de la acción humana, además de considerar que pueden diseñar políticas públicas de acuerdo a sus intereses particulares y, más aún, imponerlas al resto por medio de la coacción del gobierno. Por lo tanto, “cobra así justificación aparente la actitud de aquellos economistas que prosiguen tranquilamente sus estudios sin prestar mayor atención ni a las cuestiones epistemológicas ni a las objeciones formuladas respecto del positivismo" (Mises 1949, 6).

El problema del positivismo es que, además de pretender utilizar el método de las ciencias naturales para estudiar la acción humana, ${ }^{27}$ supone predicciones y resultados similares a los obtenidos en la física. Para Mises estas formulaciones permiten a los ingenieros sociales construir modelos de manipulación de datos. Se analizan unos medios dados

${ }^{27}$ El cientismo es la indiscriminada e indebida aplicación del método de las ciencias naturales al campo de la acción humana. El término es utilizado por Hayek (1952) para criticar las falacias del positivismo. Este término "describe, desde luego, una actitud que es decididamente acientífica en el pleno sentido de la palabra, puesto que implica una aplicación mecánica y acrítica de los hábitos de pensamiento a campos diferentes de aquellos en que éstos se formaron. El enfoque cientista, a diferencia del científico, no es un enfoque libre de prejuicios, sino todo lo contrario, una aproximación llena de ellos; la cual, antes de tomar en consideración la materia, pretende saber cuál es la vía más apropiada para investigarla" (Hayek 1952, 35). 
que correspondan lo más fielmente posible a una jerarquía también dada de objetivos. Por consiguiente, Rothbard (1976) muestra que para Mises los economistas que así proceden cometen el error de enfatizar el estudio de la economía en situaciones de equilibrio, con lo que el economista que participa en políticas públicas asume fines y medios humanos como conocidos e inmutables, lo que le proporciona la facultad de intervenir e imponer determinados estándares éticos. Peter Boettke señala la postura de Mises sobre la perspectiva del equilibro:

No hay nada estático ni puro en los intentos del hombre de realizar sus fines y, mientras que la estática comparativa puede proporcionar un modelo útil para explicar algún comportamiento observado, su análisis estático ignora los procesos dinámicos que están inextricablemente ligados a los intentos del hombre por mejorar su posición (...) En un mundo de cambio dinámico, algo debe estar impulsando los movimientos; una comprensión del mercado como un proceso requiere un creador de cambio. Este generador de cambio es la imaginación creativa del empresario que en su intento de obtener ganancias y evitar pérdidas impulsa el proceso del mercado. Así, en el fundamento del enfoque austríaco está el elemento emprendedor en la acción humana. (Boettke et al. 2003, 7)

Mises (1949) considera que es imposible efectuar predicciones cuantitativas en economía, ya que el economista no cuenta con la información subjetiva que están creando continuamente las personas. Así, el austríaco señala que el estudio científico de la acción humana sólo admite predicciones de tendencia. Éstas son de tipo cualitativo, teórico y relativo a los resultados de distintas formas de acción humana, además de la previsión de los desajustes y efectos de las políticas gubernamentales sobre el mercado. ${ }^{28}$ Para Mises, la praxeología no permite

${ }^{28}$ En palabras de Mises: "El conocimiento praxeológico permite predecir con certeza apodíctica las consecuencias de diversas formas de acción. Pero tales predicciones jamás nos ilustran acerca de aspectos cuantitativos (...). El error fundamental de todo enfoque cuantitativo de los problemas económicos estriba en olvidar que no existen relaciones constantes en las llamadas dimensiones económicas. No hay constancia ni permanencia en las valoraciones ni en las relaciones de intercambio entre los diversos bienes. Todas y cada una de las continuas mutaciones provocan nueva reestructuración del conjunto" (Mises 1949, 142). 
juzgar los medios ni fines de las personas, más bien se limita al análisis de las consecuencias respecto de la búsqueda del fin que se persigue (Rothbard 1976, 78). Mises sostiene que el rol del economista ha sido alterado al trabajar en políticas públicas. Los economistas tratan desesperadamente de hacer cuadrar el círculo, con la intención de defender ciertas políticas en términos científicos. Pero, los juicios particulares no son permitidos intelectualmente, y mucho menos científicamente (Rothbard 1976: 83). A partir de estos análisis, Mises muestra que la economía de mercado no sólo supera cualquier otro sistema de planificación gubernamental, sino que en última instancia sirve de fundamento para la propia civilización. También, plantea su postura definitiva sobre el rol del economista en la sociedad. Sobre la importancia de la educación económica escribe:

La aplicación práctica de las enseñanzas económicas presupone su aceptación por la opinión pública (...). La supremacía política de la opinión pública no sólo confiere a la ciencia económica particular condición en el conjunto de las ciencias y el saber; determina, además, el curso de la historia (...). El progreso de la humanidad depende, por un lado, de los descubrimientos sociales y económicos que los individuos intelectualmente mejor dotados efectúen y, por otro, de la habilidad de esas mismas u otras personas para hacer que estas ideologías sean atractivas a la mayoría. (Mises 1949, 1021)

Según Mises, la función del economista es el estudio, desarrollo y enseñanza de la ciencia económica. Esto es, explicar las condiciones que permiten alcanzar los mejores resultados posibles para la actividad económica de las personas.

Sin embargo, a través de la historia la función del economista ha cambiado. Los primeros economistas "pretendían difundir, mediante comunicaciones y escritos, entre sus conciudadanos, los descubrimientos que efectuaban. Querían influir sobre la opinión pública para que prevaleciera la política más idónea" (Mises 1949,1027). Mientras que los economistas neoclásicos adoptaron el positivismo y su estudio estático de la economía, que les permitió justificar el intervencionismo estatal. De acuerdo a Kirzner (1998), cuando los seres humanos actúan están inmersos en un proceso de creación y transmisión del conocimiento 
a través del mercado, sin que nadie lo dirija desde arriba. Además, el valor subjetivo de las acciones humanas impide al economista diseñar políticas públicas acordes a la diversidad de las personas. En este sentido, Mises señala:

La aparición del economista profesional es una secuela del intervencionismo, y actualmente no es sino un especialista que procura descubrir las fórmulas que permitan al gobierno intervenir mejor en la vida mercantil (...). Llegan a dirigir grandes bancos y corporaciones, ocupan escaños en los parlamentos y desempeñan funciones ministeriales en los gobiernos (...). Pero su filosofía les condena a una terrible estrechez de miras; vinculados a los partidos políticos y a los grupos de presión, que sólo buscan ventajas y privilegios para los suyos, caen en el más triste sectarismo. Nunca quieren considerar las repercusiones que a la larga habrán de provocar las medidas que preconizan. Sólo les importa el inmediato interés de aquellos a cuyo servicio se hallan. (Mises 1949, 1028)

Se distorsiona el rol del economista y se convierte en un ingeniero que juzga los medios y fines de las personas según sus puntos de vista y juicios éticos. Sin embargo, la ética es la disciplina que proporciona estándares para una crítica moral sobre cómo debería funcionar el comportamiento humano. En el análisis final, cada juicio de valor individual es en última instancia arbitrario y es sólo el resultado de un antojo personal, dado que la ética no es objetiva. Por esta razón, Mises considera que la economía y la praxeología son extremadamente útiles para proporcionar datos y conocimientos, con el objetivo de enmarcar la política económica, pero no puede ser suficiente por sí sola para permitir al economista formular ningún pronunciamiento de valor o abogar por cualquier política pública (Rothbard 1976, 98). Asimismo, las opiniones personales no son universalmente compartidas. Boettke (1995) plantea que la ventaja del análisis praxeológico frente al positivismo es que la crítica de Mises, por ejemplo, a ciertas políticas gubernamentales nunca se desenvuelve como una crítica hacia los fines de dicho intervencionismo. Los fines no están en disputa, pero sí los efectos económicos de los medios escogidos para alcanzar los objetivos de determinada política pública en el proceso de cooperación e intercambio social. 
Mises fue un defensor del libre mercado en una época en que el mundo estaba inclinado hacia el colectivismo y un Estado poderoso. Además, fue un solitario que promovía las enseñanzas de una sociedad libre en un mundo que no sólo lo ignoraba, sino que también iba en la dirección contraria a sus planteamientos. Por eso, fue excluido de la profesión dominada por el paradigma neoclásico y sus aportes a la ciencia económica no fueron reconocidos. No obstante, la misión educadora de Mises tuvo efecto en sus estudiantes, quienes consolidaron la moderna escuela austríaca de economía. En palabras de Zanotti:

Mises murió un año antes de lo que se considera el año del Austrian Revival (1974), cuando Hayek obtiene el Premio Nobel y una serie de importantes pensadores, casi todos discípulos o contemporáneos de Hayek o Machlup (por ejemplo L. Lachmann), se reúnen en el Institute for Humane Studies para ofrecer una serie de conferencias sobre la Escuela Austríaca. Nada de esto hubiera sucedido sin la persistencia y perseverancia de Ludwig von Mises. (Zanotti 2010, 116)

Del mismo modo, Gottfried von Haberler y Fritz Machlup, ambos discípulos de Mises, fueron presidentes de la American Economics Association entre los años 1950-1953 y 1971-1974, respectivamente. Esta asociación consideró a Mises como Distinguished Fellow en 1969. Si bien Mises fue aislado por la profesión de economistas, son sus discípulos los encargados de divulgar sus enseñanzas. Así lo señalan Bien Greaves y McGee (1993, 1995). Importantes economistas del siglo XX leyeron a Mises, como Abba Lerner (1934, 1935), Alfred MüllerArmack (1947), Milton Friedman (1972), John Chamberlain (1973), Gottfried Harberler (1982), Friedrich Hayek (1982), James Buchanan (1987), entre otros. ${ }^{29}$

Ludwig von Mises, en su labor como educador económico, también influyó en el ámbito político, ya que logró un cambio de orientación en las políticas públicas en Alemania a través de "Ludwig Erhard, el artífice del milagro alemán, quien fue influido fuertemente por Wilhelm Röpke, que conocía bien a Mises (lo mismo sucedió con Luigi Einaudi y Jacques Rueff)" (Zanotti 2010, 115). Igualmente, Mises dictó

${ }^{29}$ La lista completa se encuentra en Bien Greaves y McGee $(1993,1995)$. 
conferencias en México (1942) ${ }^{30}$ y Argentina (1959) 31 sobre coyuntura, políticas e ideas de una sociedad libre. Siempre insistió en que "la mejor política económica es limitar la acción del gobierno a crear las condiciones para que las personas puedan seguir sus propios objetivos, cooperar, y vivir en paz con sus vecinos" (Mises 1959, 4). ${ }^{32}$ Nunca dejó de ser un profeta, cuya misión era ayudar a la civilización por medio de la educación económica de las personas. En efecto, dijo Mises:

No se puede relegar la economía al estrecho marco de las aulas universitarias, a las oficinas de estadística o a círculos esotéricos. Es la filosofía de la vida y de la actividad humana y afecta a todos y a todo. Es la base misma de la civilización y de la propia existencia del hombre. (Mises 1949, 1037)

Finalmente, Ludwig von Mises fallece un 10 de octubre de 1973 en New York, USA, habiendo publicado veintidós libros y doscientos trece ensayos (Bien Greaves y McGee 1993, 1995).

\section{CONCLUSIÓN}

La vida y obra de Ludwig von Mises nos enseñan que el economista debe ser neutral a la hora de estudiar los fenómenos económicos y las políticas públicas. Su función debe ser la educación económica (a los hombres de negocios y las personas en general), además de contribuir al desarrollo de la ciencia. El economista no debe intervenir en la vida de las personas, sino explicar los fundamentos e implicancias últimas de los distintos cursos de acción en el proceso de cooperación e intercambio social.

${ }^{30}$ En 1942, el secretario de Hacienda y Crédito Público de México, Luis Montes de Oca, invitó a Mises para visitar su país y dar una serie de conferencias en la Escuela de Economía de la Universidad Nacional Autónoma de México y en la Escuela Libre de Derecho. Además, Mises dictó dos conferencias para la Asociación de Banqueros de México y la Cámara de Industria Minera, las que le propusieron prolongar su estancia (Romero 2011, 26-27).

${ }^{31}$ Cuenta Margit von Mises que visitó Argentina junto a su esposo en 1959, invitados por el Dr. Alberto Benegas Lynch, para dictar una serie de conferencias en la Universidad de Buenos Aires sobre capitalismo, socialismo, intervencionismo, políticas e ideas (Mises 1959, 6).

${ }^{32}$ La cursiva es mía. 
Sin embargo, en la mirada de Mises, existe entre los economistas profesionales un desinterés sobre el estudio de metodología y epistemología, ya que su formación universitaria se basa únicamente en bibliografía referente al enfoque del equilibrio de Cambridge-Lausanne, por lo que no ven problemas al aplicar las técnicas propias de las ciencias naturales a las ciencias sociales, en general, y a la ciencia económica, en particular. Mises veía cómo la formación económica en las universidades consistía en preparar ingenieros, mediante el uso de manuales destinados a divulgar terminologías, junto con reemplazar el análisis económico por fórmulas y ecuaciones que recogen unos hipotéticos estados de equilibrio, donde se ignora la acción humana.

Aunque en sus comienzos era partidario del historicismo y el socialismo, se interesa en epistemología y metodología, junto con apreciar el papel que cumplen las ideas en la sociedad. Por eso, sus esfuerzos intelectuales en torno a coyuntura y políticas públicas se extendían a estudiantes, académicos y empresarios, ministros, periodistas y amas de casa. Siempre concedía gran importancia a la difusión para el hombre de negocios y el público en general (Rothbard 1988, 53). Por último, Mises nunca dejó de manifestar la importancia del rol del economista, como teórico y educador, para la existencia humana:

El género humano decidirá si quiere hacer uso adecuado del inapreciable tesoro de conocimientos que este acervo supone o si, por el contrario, prefiere no utilizarlo. Si los hombres deciden prescindir de tan espléndidos hallazgos y menospreciar sus enseñanzas, no por ello ciertamente desvirtuará la ciencia económica; se limitarán a destruir la sociedad y el género humano. (Mises 1949, 1046)

\section{REFERENCIAS}

Anderson, William P. 2004. "Mises versus Weber on Bureaucracy and Sociological Method". Journal of Libertarian Studies 18: 1-30.

Backhouse, Roger E. 2000. "Austrian Economics and the Mainstream: View from the Boundary". Quarterly Journal of Austrian Economics 3 (2): 31-43.

Benegas Lynch (h), Alberto. 1991. "Acerca del pensamiento de Ludwig von Mises. Introducción y una antología”. Estudios Públicos 42.

- 1993. Hacia el autogobierno. Una crítica al poder político. Buenos Aires: Emecé Editores. 
Bien Greaves, Bettina. 1994. "Ludwig von Mises and The Coming of Socialism in Austria”. Austrian Economics Newsletter 14 (2).

Bien Greaves, Bettina \& Robert. W. McGee. 1993. Mises. An Annotated Bibliography. New York: Foundation for Economic Education.

_. 1995. Mises. An Annotated Bibliography: 1982-1993 Update. New York: Foundation for Economic Education.

Boettke, Peter. 1987. "Economists \& Liberty: Ludwig von Mises (1881-1973)". Nomos (July/August): 8-11.

1995. "Why Are There No Austrian Socialists? Ideology, Science and the Austrian School". Journal of the History of Economic Thought 17 (1): 35-56.

1996. "What Is Wrong with Neoclassical Economics (and What Is Still Wrong with Austrian Economics)". En Beyond Neoclassical Economics, editado por Fred Foldvary. Chentelham: Edward Elgar Publishing.

2010. Handbook on Contemporary Austrian Economics. MA: Edward Elgar.

Boettke, Peter, Peter Leeson \& Christopher Coyne. 2003. Man as Machine: The Plight of 20th Century Economics. Working Paper 17. Mercadus Center, George Mason University.

Cachanosky, Juan Carlos. 2008. "La escuela austríaca de economía”. Revista de Instituciones, Ideas y Mercados 49: 16-55.

Caldwell, Bruce. 1990. "Does Methodology Matter? How Should It Be Practiced”. Finnish Economic Papers 3 (1): 64-71.

Crespo, Ricardo F. 1997. "Max Weber and Ludwig von Mises, and the Methodology of the Social Sciences". En Methodology of the Social Sciences, Ethics, and Economics in the Newer Historical School. Berlin-Heidelberg: Springer.

Ebeling, Richard. M. 2004. "Mission to Moscow: 'The Mystery of the Lost Papers of Ludwig von Mises". Evenings at Foundation for Economic Education.

Föllmer, Hans \& Uwe Küchler. 1998. "Richard von Mises". En Mathematics in Berlin, editado por Heinrich G. W. Begehr et al. Basel: Birkhäuser.

Hayek, Friedrich A. 1952. La contrarrevolución de la ciencia. Madrid: Unión Editorial S. A.

Hunold, Albert. 1961. "How Mises Changed My Mind". The Mont Pelerin Quarterly III (3): 16.

Hülsmann, Jörg G. 2007. Mises: The Last Knight of Liberalism. Alabama: Ludwig von Mises Institute.

Kirzner, Israel M. 1998. "El empresario". Revista Libertas 29. http://www.eseade. edu.ar/files/Libertas/16_3_Kirzner.pdf.

- 2001. Ludwig von Mises: The Man and His Economics. Delaware: Library of Modern Thinkers.

Lavoie, Don. 1981. "A Critique of the Standard Account of the Socialist Calculation Debate". Journal of Libertarian Studies V (1): 41-87. 
Menger, Carl. 1871. Principles of Economics. Alabama: Ludwig von Mises Institute.

Mises, Margit von. 1976. My Years with Ludwig von Mises. New York: Arlington House.

Mises, Ludwig von. 1912. Teoría del dinero y del crédito. Madrid: Unión Editorial S. A.

-1919. Nación, Estado y economía. Madrid: Unión Editorial S. A.

. 1920. Economic Calculation in the Socialist Commonwealth. Alabama: Ludwig von Mises Institute.

. 1922. El socialismo. Análisis económico y sociológico. Madrid: Unión Editorial S. A.

-1927. Liberalismo. La tradición clásica. Madrid: Unión Editorial S. A.

. 1933. Problemas epistemológicos en economía. Madrid: Unión Editorial S. A.

. 1949. La acción humana. Tratado de economía. Madrid: Unión Editorial S. A.

-1959. Politica económica. Pensamiento para hoy y para el futuro. Alabama: Ludwig von Mises Institute.

—. 1962. Los fundamentos últimos de la ciencia económica. Madrid: Unión Editorial S. A.

- 1986. Planificación para la libertad y otros ensayos. Buenos Aires: Centro de Estudios sobre la Libertad.

- 2000. The Political Economy of International Reform and Reconstruction, editado por R. M. Ebeling. Indiana: Liberty Fund.

- 2002. Between the Two World Wars: Monetary Disorder, Interventionism, Socialism, and the Great Depression, editado por R. M. Ebeling. Indiana: Liberty Fund.

- 2012. Monetary and Economic Policy Problems Before, During, and After the Great War, editado por R. M. Ebeling. Indiana: Liberty Fund.

Mises, Ludwig von \& Hans F. Sennholz. 1978. Ludwig von Mises: Notes and Recollections. South Holland, III: Libertarian Press.

Muñoz, Blanca. 2004. "Escuela de Frankfurt". Departamento de Sociología, Universidad Carlos III de Madrid. http://www.archivochile.com/Ideas Autores/esc_frankf_s/esc_frankf_sobre0007.pdf.

Rodríguez, José Carlos. 2009. “Ludwig von Mises”. Libertad Digital. http://www. libertaddigital.com/opinion/historia/ludwig-von-mises-1276237165.html.

Romero Sotelo, María E. 2011. "Las raíces de la ortodoxia en México". Economía UNAM 8 (24): 23-50.

Rothbard, Murray N. 1973. Lo esencial de Ludwig von Mises. Madrid: Unión Editorial S. A.

- 1976. "Praxeology, Value Judgments, and Public Policy". En The Foundations of Modern Austrian Economics, editado por Edwin Dolan. Kansas City: Sheed and War. 
1988. Ludwig von Mises. Scholar, Creator, Hero. Alabama: Ludwig von Mises Institute.

- 1993. "Mises and the Role of the Economist in Public Policy". En The Meaning of Ludwig von Mises: Contributions in Economics, Sociology, Epistemology, and Political Philosophy, editado por Jeffrey M. Herbener. Alabama: Mises Institute.

Schulak, Eugen-Maria \& Herbert Unterköfler. 2011. The Austrian School of Economics: A History of Its Ideas, Ambassadors, and Institutions. Alabama: Ludwig von Mises Institute.

Siegmund-Schultze, Reinhard. 2001. "Richard von Mises". En Statisticians of the Centuries. New York: Springer.

Zanotti, Gabriel J. 2010. "La filosofía política de Ludwig von Mises". Procesos de Mercado 7 (2): 109-146. EP 